\title{
Empirical Analysis on the Influence of Rail Transit Network on the Compact Development of China's Metropolitan Areas
}

\author{
Weiwei Hao ${ }^{a^{*}}$, Hongyan $\mathrm{Gao}^{\mathrm{b}}$, and Zongqing $\mathrm{Liu}^{\mathrm{c}}$ \\ School of Economics and Management \\ Beijing Jiaotong University \\ Beijing, China \\ avivihao1014@163.com, bhygao@bjtu.edu.cn, c12113103@bjtu.edu.cn \\ ${ }^{*}$ Corresponding author
}

\begin{abstract}
Keywords: Metropolitan area; Rail transit network; Compact development; Efficiency evaluation
\end{abstract}
\begin{abstract}
As the backbone of the comprehensive transportation system, rail transit network has significant support and guidance on the formation and development of metropolitan area. Firstly, this paper constructs the Rail Transit-Compactness of metropolitan area model to explore the empirical effect from rail transit on the compactness with the data of China's top ten metropolitan areas. Secondly, use DEA to evaluate the efficiency of rail transit network of China's top ten metropolitan areas. Thirdly, results show the rail transit variables have a significant positive impact on the compactness of metropolitan area, but this effect has time lag. The efficiency of rail transit network with China's top ten metropolitan areas still need to be improved. Lastly, analyze the causes hindering the efficiency improvement of rail transit network and give some suggestions to these problems respectively.
\end{abstract}

\section{Introduction}

As the foundation of economic and social development, transportation plays an important role in supporting and guiding the formation and development of metropolitan area. As the backbone of the comprehensive transportation system, rail transit is an important channel connecting cities and towns in metropolitan area. With the increase of rail transit scale and density, rail transit tends to be network, which can effectively shorten the time and space distance among cities in the metropolitan area, guide the reasonable spatial distribution of population and economic activities, and provide a solid foundation to realize the integration development of metropolitan area.

Rail transport in metropolitan area, between the inter-regional transport and urban transport, still faces many problems. For example, rail transit network has not yet formed, the transport structure is unreasonable, the suburban railway is lagging behind, and the comprehensive transportation hub is at the stage of the start. Meanwhile, there is still a certain distance to go before it catches up with the world-class metropolitan areas, which have developed efficient rail transport network. New York metropolitan area has formed efficient rail transport network system with subway and commuter rail; the rail transport network in Paris metropolitan area radiates outward from the city center, including subway, circular-city railway and suburban railway; the Tokyo metropolitan area has reached to be 3,100 kilometers of rail transit with 2,500 kilometers of commuter rail. The direction of China's urbanization is to develop towards metropolitan area. The rail transit is an important way to guide and support the rapid development of metropolitan area, which is of great significance for promoting the compact development of metropolitan area.

\section{The empirical analysis of rail transit-compactness of metropolitan areas model}

Previous theories and researches have concluded that rail transit is the important factor affecting the compact development of metropolitan area. Otherwise, this point has not been verified in China. Thus, 
this paper constructs the rail transit- compactness of metropolitan area model to explore the influence from rail transit on the compact development of metropolitan area.

\subsection{Model specification}

To explore the exact relationship between rail transit and the compact development in metropolitan area, rail transit variables are taken as main explanatory variables, and the compactness of metropolitan area as explained variable, the rail transit-compactness of metropolitan area multiple regression model is constructed as follows:

$$
\text { Comp }_{i j t}=F\left(\text { Trans }_{i j t}, X_{i j t}\right)
$$

Comp $_{i j t}$ is the compactness of metropolitan $\mathrm{i}$ in $\mathrm{t}$ year; Trans $\mathrm{ijt}_{\mathrm{ijt}}$ presents the different rail transit variables $\mathrm{j}$; $\mathrm{X}_{\mathrm{ijt}}$ presents other relevant control variables, such as the proportion of secondary and tertiary industries in GDP, population density, capital density, the proportion of urban population in total population, and the output level of per unit built-up area, which all can affect the compact development of metropolitan area.

In essence, the effect of rail transit on metropolitan area's compactness is not a simple linear relationship. In the initial stage, rail transit extended linearly, and the population and economic activities also expanded along the rail transit lines, which destroyed the integrity of metropolitan area's spatial shape, and reduced the compactness level to some extent. However, as the undeveloped land among rail transits is gradually filled with population and various economic activities, the integrity and compactness of the metropolitan area will increase. Therefore, take the form of logarithm on both sides, as follows:

$$
\ln \operatorname{Comp}_{i j t}=\alpha+\beta \ln \operatorname{Trans}_{i j t}+\sigma \ln X_{i j t}+u_{i j t}
$$

However, the changes in the compactness of metropolitan area also have some influence on the rail transit. As the further land development in metropolitan area, it will bring more traffic demand, which requires more traffic supply. Therefore, the changes of compactness in metropolitan area can urge some regional transportation administrative departments to further improve rail transit system and increase the transport supply to meet the increasing traffic demand. In order to control the endogenous causal relationship in the model, one-year lagged explanatory variables and explained variable are added in the model, as follows:

$$
\ln \text { Comp }_{i j t}=\alpha+\beta \ln \operatorname{Trans}_{i j t}+\delta_{0} \ln \text { Trans }_{i j t-1}+\theta_{0} \ln \text { Comp }_{i j t-1}+\sigma \ln X_{i j t}+u_{i j t}
$$

\subsection{Variables and data sources}

\subsubsection{Rail transit variables of metropolitan area}

In general, the main indicators for measuring the development level of rail transit infrastructure include the network scale (Xumei Chen, Hualei Tong, Shilian Gao, 2001; Yuqin Zhu, Yihua Chen, Hongbing Wu, 2007, etc.), network coverage (Wenjun Guo, Qian Liu, 2003; Guogang Gao, 2014) and network density (Yuxian Hu, 2008; Ke Yang, 2016). Since the current statistics about rail transit in China's metropolitan area are mostly attributed to railway transportation industry, this paper uses the number of employed people in the railway transportation industry as one of the indicators for measuring the development of rail transit network. The more employees, the higher development level of rail transit. Finally, this paper selects the following three indicators to measure the metropolitan area's rail transit variable (Trans): the network scale (len), the density of line network (den) and the railway transportation employment (emp).

\subsubsection{The compactness variable of metropolitan area}

Based on the compactness measurement model from Chuanglin Fang, Weifeng Qi and Jitao Song (2008), the comprehensive compactness of metropolitan area is measured based on the compactness of five production factors, which are industry compactness, space compactness, capital compactness 
and transport compactness. According to "China Statistical Yearbook (2002 2014)", "China Urban Statistical Yearbook (2001 2014)", and the provincial or municipal statistics yearbook (2001 2014), we calculate and obtain the comprehensive compactness of China's top ten metropolitan areas from 2001 to 2013.

\subsection{Result analysis}

Panel least square method and generalized moment estimation method (GMM) are used to estimate the impact of rail transit on metropolitan area's compactness. To avoid the interaction between traffic variables and their lagged terms, the terms are estimated independently and the results are as follows:

Table 1. The estimated result of fixed-effect model from rail transport - metropolitan area compactness

\begin{tabular}{|c|c|c|}
\hline Model & 1 & 2 \\
\hline Dependent Variable & \multicolumn{2}{|c|}{ Compactness(comp) } \\
\hline $\begin{array}{c}\text { emp } \\
\text { (logged) }\end{array}$ & $\begin{array}{l}0.032 \\
(1.91)\end{array}$ & - \\
\hline $\begin{array}{c}\text { len } \\
\text { (logged) }\end{array}$ & $\begin{array}{l}0.305 * * * \\
(4.78)\end{array}$ & - \\
\hline $\begin{array}{c}\text { den } \\
\text { (logged) }\end{array}$ & $\begin{array}{l}0.177 * * * \\
(4.23)\end{array}$ & - \\
\hline $\begin{array}{l}\text { emp_lag1 } \\
\text { (logged) }\end{array}$ & - & $\begin{array}{l}0.037 \\
(1.97)\end{array}$ \\
\hline $\begin{array}{l}\text { len_lag1 } \\
\text { (logged) }\end{array}$ & - & $\begin{array}{c}0.322 * * * \\
(3.84)\end{array}$ \\
\hline $\begin{array}{l}\text { den_lag1 } \\
\text { (logged) }\end{array}$ & - & $\begin{array}{l}0.198 * * * \\
\quad(3.31)\end{array}$ \\
\hline constant & $\begin{array}{l}-0.589 \\
(-2.22) \\
\end{array}$ & $\begin{array}{l}-0.581 \\
(-1.90) \\
\end{array}$ \\
\hline control variable & omitted & omitted \\
\hline $\mathrm{R}^{2}$ & 0.7961 & 0.7695 \\
\hline Prob(F-statistic) & 0.0000 & 0.0000 \\
\hline
\end{tabular}

Note: $* \mathrm{p}<0.1 ; * * \mathrm{p}<0.05 ; * * * \mathrm{p}<0.01$.

From the results in the above table, it can be seen that rail transit variables have a significant relationship with the compactness of metropolitan area. As the backbone of metropolitan area, rail transit is an important factor that affects the compact development of metropolitan area and plays a positive role in promoting the compactness of metropolitan area. In addition to the variable of employment from railway transportation industry, other rail transit variables all present some positive significant effect on the compactness. Model 2 estimates the effect of one-year lagged rail transit variables on the compactness. It reveals that the effect from one-year lagged rail transit variables are slightly larger than the current traffic variables, which means that there is a significant time-lag on the effect from rail transit variables on the compactness of metropolitan area.

Table 2 shows the Stata output results of system GMM one-step estimation. In order to distinguish the different effects of rail transit variables and their lagged terms on the compactness of metropolitan area, separate estimates were also made (see model 3 and model 4). In model 3 and model 4, the estimated coefficients of lagged compactness variables are 1.050 and 1.064 respectively, both of which are significant at $1 \%$ level. However, the impact of rail transit variables is somewhat complicated. The employment (emp) and network scale (len) are significant at 1\% and 5\% respectively, but the correlation coefficient of emp is negative (-0.011), which means that the number of employed people in the rail transport industry is negatively correlated with the compactness of metropolitan area. In model 4, the one-year lagged rail transit variables also show obvious correlation with the compactness 
of metropolitan area, and correlation coefficients of the employment in rail transport industry (emp) and network scale (len) are 0.069 and 0.018 respectively.

Table 2.The estimated result of GMM model from rail transit- metropolitan area compactness

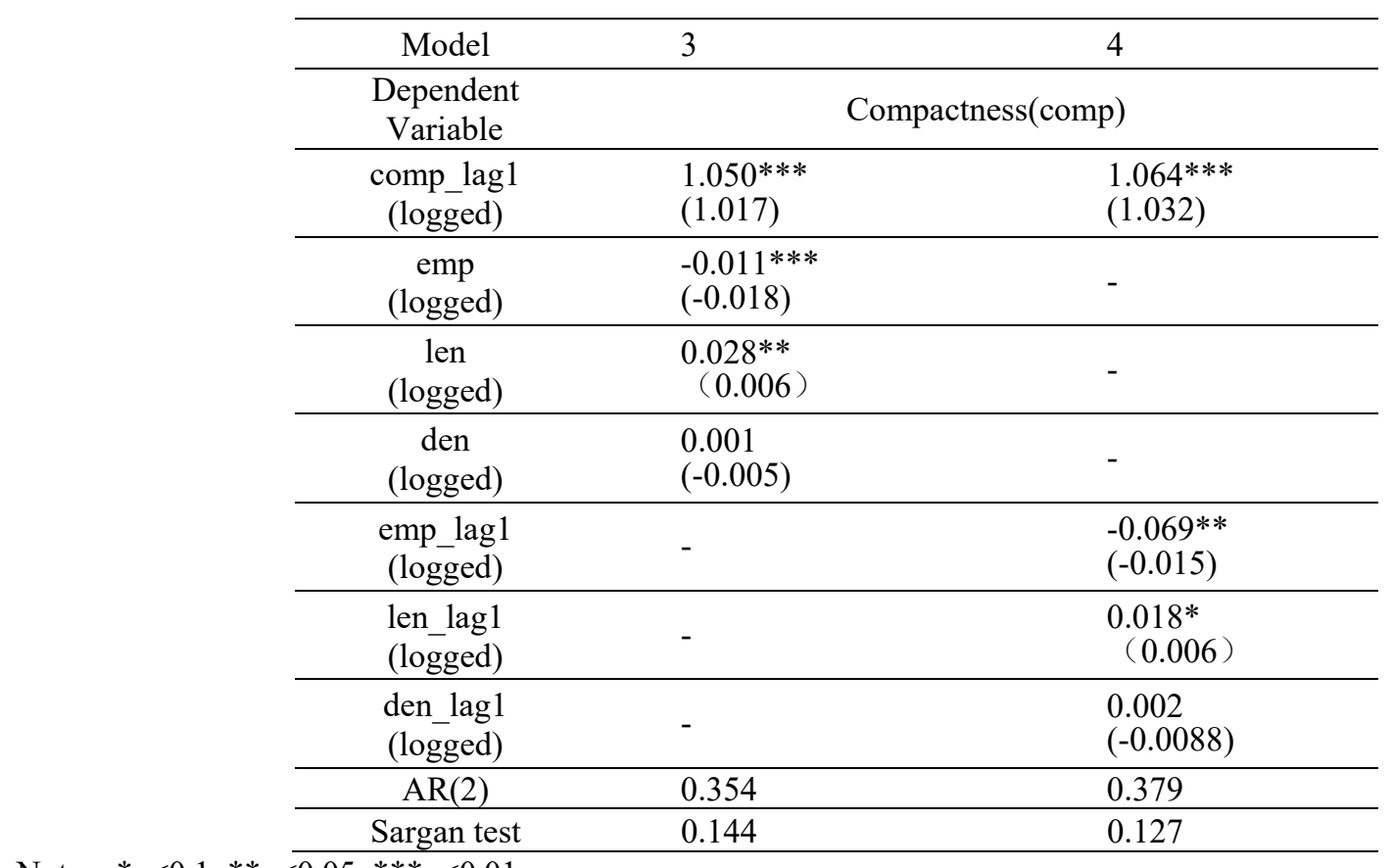

Note: $* \mathrm{p}<0.1 ; * * \mathrm{p}<0.05 ; * * * \mathrm{p}<0.01$

\section{Efficiency evaluation of rail transit network based on DEA}

In order to improve rail transit network and promote the compact development of metropolitan area, this paper uses DEA to evaluate the efficiency of rail transit network with China's top ten metropolitan areas.

\subsection{Selection of input index}

Inputs of metropolitan area's rail transit network can be divided into infrastructure input and operational service input. The specific indexes include: the number of employment, the scale of line network, the number of hubs, the area density of line network and the population density of line network.

\subsection{Selection of output index}

Outputs of metropolitan area's rail transit network are mainly realized by economic benefits. Economic benefits of rail transit network mainly come from the land appreciation and the economic development by construction and operation of rail transit network. In this paper, the specific indicators of reflecting the economic benefits are divided into the following categories: first is the passenger volume and freight volume of reflecting rail transit network capacity; second is the proportion of the second and tertiary industry to reflect the influence of rail transit network on the optimization of the industrial structure; third is the index of spatial economy linkages for the influence of rail transit network on the inter-city connection; fourth is the maximum difference from cities with per capita GDP to reflect the influence from rail transit network on narrowing the regional economic difference.

\subsection{The decomposition characteristics of rail transit network efficiency}

Using the DEA model, we calculate the technical efficiency, pure technical efficiency and scale efficiency of rail transit network with China's top ten metropolitan areas in 2001 and 2013 by using DEAP2.1 software (Table 3). 
It can be seen from the table that the average technical efficiency of top ten metropolitan areas in 2010 and 2013 are 0.847 and 0.936 respectively, reaching the optimal level of $85 \%$ to $94 \%$. In 2001 , there are six metropolitan areas reaching the technical efficiency of DEA, including ChengduChongqing, Guan Zhong, the west side of the Straits, Beijing-Tianjin-Hebei, the middle reaches of Yangtze River, the Yangtze River Delta metropolitan areas, and the other four metropolitan areas are non-DEA efficient. The technical efficiency of rail transit network in the Pearl River Delta is the lowest, only 0.459 , which means the rail transit network scale in Pearl River Delta need to be improved; in 2013, there are six metropolitan areas reaching effective technology efficiency of DEA. The technical efficiency of rail transit network in Shandong Peninsula is a minimum of 0.596, while in 2001, the minimum technical efficiency of Pearl River Delta has a great increase, which reveals the scale of rail transit network in the Pearl River Delta has been greatly improved during these 13 years.

In 2001 and 2013, the numbers of metropolitan area with the optimal efficiency of pure technology are nine and ten respectively. The number of metropolitan area with the most comprehensive technical efficiency is six; the number of metropolitan area with the optimal scale efficiency is also six, so it can be seen that the optimal metropolitan area with pure technical efficiency is more than that of the optimal comprehensive technical efficiency and the optimal scale efficiency. Only pure technical efficiency of Shandong Peninsula metropolitan area in 2001 isn't effective, which means factor input structure of the rail transit network is unreasonable. In 2013, the pure technical efficiency of all the metropolitan areas is effective, and the technical efficiency of Shandong Peninsula turns to be effective, indicating that it has made some adjustments on the elements inputs from 2001 to 2013.

Scale efficiency is the decisive factor of technical efficiency. In 2001, Chengdu-Chongqing, Guan Zhong, the west side of the Straits, Beijing-Tianjin-Hebei, the middle reaches of the Yangtze River and the Yangtze River Delta are constant returns to scale, indicating that these metropolitan areas have reached the optimal scale, while South Liaoning, Shandong Peninsula, Central Plains and the Yangtze River Delta metropolitan area as the scale of diminishing returns, show that these metropolitan area should be appropriate to reduce the inputs. The trend in 2013 is the same with that in 2001, including that South Liaoning, Shandong Peninsula, Central Plains and the Yangtze River Delta are decreasing returns to scale, but compared with 2001, the scale efficiency has increased, which means the metropolitan area have reduced unnecessary input scale to a certain extent for increasing output ${ }^{[1]}$.

Table 3. Network efficiency estimation of rail transits from top ten metropolitan areas in China

\begin{tabular}{ccccccccc}
\hline $\begin{array}{c}\text { Metropolitan } \\
\text { area }\end{array}$ & \multicolumn{1}{c}{ ef } & pe & se & sb & ef & pe & se & sb \\
\hline CY & 1.000 & 1.000 & 1.000 & invariant & 1.000 & 1.000 & 1.000 & invariant \\
\hline GZ & 1.000 & 1.000 & 1.000 & invariant & 1.000 & 1.000 & 1.000 & invariant \\
\hline WS & 1.000 & 1.000 & 1.000 & invariant & 1.000 & 1.000 & 1.000 & invariant \\
\hline JJ & 1.000 & 1.000 & 1.000 & invariant & 1.000 & 1.000 & 1.000 & invariant \\
\hline SL & 0.686 & 1.000 & 0.686 & descending & 0.812 & 1.000 & 0.812 & descending \\
\hline SP & 0.483 & 0.829 & 0.582 & descending & 0.596 & 1.000 & 0.596 & descending \\
\hline MY & 1.000 & 1.000 & 1.000 & invariant & 1.000 & 1.000 & 1.000 & invariant \\
\hline YD & 1.000 & 1.000 & 1.000 & invariant & 1.000 & 1.000 & 1.000 & invariant \\
\hline CP & 0.838 & 1.000 & 0.838 & descending & 0.979 & 1.000 & 0.979 & descending \\
\hline PD & 0.459 & 1.000 & 0.459 & descending & 0.971 & 1.000 & 0.971 & descending \\
\hline Average & 0.847 & 0.983 & 0.857 & - & 0.936 & 1.000 & 0.936 & -
\end{tabular}

Note: CY is Chengdu-Chongqing; GZ is Guan Zhong; WS is the west side of the Straits; JJJ is JingJin-Ji; SP is Shandong Peninsula; MY is the middle reach of Yangtze River; YD is Yangtze River Delta; CP is the Central Plains; PD is Pearl River Delta; ef is technical efficiency; pe is pure technical efficiency; se is scale efficiency; sb is scale benefit. 


\section{Conclusions and suggestions}

From the above models and empirical analysis, two conclusions can be drawn as follows:

For one thing, based on the estimated results from the rail transit-compactness of metropolitan area model, it reveals that the rail transit variables have a significant positive impact on the compactness of the metropolitan area, but this effect has time lag. It means that it is effective to guide and promote the compact development of metropolitan area by further improving the infrastructure and services of rail transit network.

For another, from the empirical analysis through DEA, the efficiency of rail transit network in China's top ten metropolitan areas has increased from 2001 to 2013 to some extent, but the efficiency of rail transit network still need to be improved, which cannot maximize the network effect and support the compact development of metropolitan area effectively. There are still many factors hindering the development of rail transit network in metropolitan area. Thus, some specific suggestions are put forward:

Firstly, the scale of rail transit network remains to be increased. It is necessary to strengthen the rail transit infrastructure construction and increase the scale and the density of rail transit network as soon as possible, so as to improve the scale efficiency of the rail transit network. Secondly, the technical level of rail transit needs to be improved. The increase of technology input, the introduction and application of new equipment, such as route-design upgrades, scheduling technology reform and so on, all can improve rail transit passenger and freight capacity. Thirdly, the operation and management level of rail transit network still need to be improved. The structure of rail transit network in metropolitan area is unreasonable, such as the lack of inter-city railway, suburban railway construction lagging behind, unestablished comprehensive transportation hubs and so on. Therefore, it is necessary to actively improve rail transport services and management level and promote the effective allocation of resources, so as to enhance the technology efficiency of rail transit network.

\section{References}

[1] J. $\mathrm{Xu}$ and $\mathrm{X} . \mathrm{Xu}$, Urban land use efficiency and its change of the Yangtze River Delta based on data envelopment analysis, World Regional Studies, vol.22, no.3, pp. 121-129, 2013.

[2] D. Alexander and R. Tomalty, Smart growth and Sustainable development: challenges, solutions and policy directions, Local Environment, vol.7, no.4, pp. 397-409, 2002.

[3] J. Willigers and B. Wee, High-speed rail and office location choices_-A stated choice experiment for the Netherlands, Journal of Transport Geography, vol.19, no.4, pp. 745-754, 2011.

[4] J. Gutiérrez, Location, economic potential and daily accessibility: an analysis of the accessibility impact of the high-speed line Madrid-Barcelona-French border, Journal of Transport Geography, vol.9, no.4, pp. 229-242, 2001.

[5] J. Berechman and D. Ozmen, Empirical analysis of transportation investment and economic development at state, county and municipality levels, Transportation, vol.33, no.6, pp.537-551, 2006.

[6] R. Ewing and S. Hamidi, Compactness versus sprawl: a review of recent evidence from United States, Journal of Planning Literature, vol.30, no.4, pp. 413-432, 2015. 